\title{
Pengaruh Pemberian Pupuk Nanosilika terhadap Tinggi Tanaman dan Jumlah Anakan Padi Beras Merah (Oryza sativa L.var. indica)
}

\section{The Effect of Nanosilica Fertilizer to Height and Number of Tillers of Red Rice (Oryza sativa L.var. indica)}

\author{
Skolastika Dara Sabatini ${ }^{1}$, Rini Budihastuti ${ }^{2}$, Sri Widodo Agung Suedy ${ }^{2 *}$ \\ ${ }^{1)}$ Program Studi Biologi, Departemen Biologi, Fakultas Sains dan Matematika, Universitas Diponegoro \\ ${ }^{2)}$ Departemen Biologi, Fakultas Sains dan Matematika, Universitas Diponegoro \\ Jl. Prof. Soedarto, SH, Tembalang, Semarang \\ *Email: agung.suedy@gmail.com
}

Diterima 16 Februari 2017 / Disetujui 28 Agustus 2017

\begin{abstract}
ABSTRAK
Padi beras merah (Oryza sativa L. var. indica) merupakan salah satu pangan fungsional. Selain kaya karbohidrat, beras merah juga mengandung antosianin sebagai antioksidan yang bermanfaat untuk kesehatan manusia. Kendala budidaya padi merah saat ini adalah pertumbuhan dan produksi yang masih rendah. Pertumbuhan dan produktivitas padi yang rendah, antara lain dapat disebabkan oleh ketersediaan Silika (Si) yang rendah. Lahan pertanian di Indonesia banyak mengalami leaching sehingga Si yang tersedia di tanah sawah tidak banding lurus dengan kandungan totalnya. Silika merupakan unsur yang memiliki peran penting dalam meningkatkan pertumbuhan tanaman khususnya kelompok Gramineae seperti padi. Silika dibutuhkan tanaman monokotil akumulator yang dapat mendukung pertumbuhan karena dapat memperbaiki proses fotosintesis. Aplikasi penggunaan silika saat ini dikembangkan dalam bentuk nanosilika karena langsung mencapai target, dan dibutuhkan dalam jumlah yang sedikit. Penelitian ini bertujuan untuk mengkaji pengaruh pupuk nanosilika terhadap pertumbuhan tinggi tanaman, jumlah anakan dan pola pertumbuhannya. Penelitian ini menggunakan Rancangan Acak Lengkap dengan perlakuan konsentrasi pupuk nanosilika yaitu: P0 $(0 \mathrm{ml} / \mathrm{L}), \mathrm{P} 1(2,5 \mathrm{ml} / \mathrm{L}), \mathrm{P} 2(5 \mathrm{ml} / \mathrm{L}), \mathrm{P} 3(7,5 \mathrm{ml} / \mathrm{L}), \mathrm{P} 4(10 \mathrm{ml} / \mathrm{L})$. Parameter pertumbuhan yang diamati yaitu tinggi tanaman, jumlah anakan dan pola pertambahan tinggi tanaman serta jumlah anakan dari 10-40 HST. Data dianalisis dengan Analysis of Variance (ANOVA) dan dilanjutkan dengan uji Duncan's Multiple Range Test (DMRT) pada taraf signifikansi 95\%. Hasil penelitian yang didapat adalah perlakuan pupuk nanosilika P1-P4 memberikan hasil peningkatan tinggi tanaman dan jumlah anakan padi beras merah. Perlakuan P4 $(10 \mathrm{ml} / \mathrm{L})$ memberikan pengaruh yang paling baik dan hasil tertinggi yaitu tinggi tanaman $106,40 \mathrm{~cm}$ dan jumlah anakan 40,20 anakan. Pola pertumbuhan tinggi tanaman cenderung masih meningkat sampai 40 HST, namun pola pertumbuhan anakan vegetatif cenderung melambat pada 40 HST.
\end{abstract}

\section{Kata kunci : beras merah, pertumbuhan, nanosilika}

\section{ABSTRACT}

Brown rice (Oryza sativa L. var. indica) is one of the functional food, because it has important benefits for human health due to containing high fiber and anthocyanin for antioxidant so consumer demand is increasing. The obstacles of red rice cultivation are the low growth and production. The low rice growth and productivity can be caused availability of silica ( $\mathrm{Si}$ ) limited on wetland. Agricultural land in Indonesia had leaching so available Si in the wetland is not proportional with content Si total. Silica is an element that has an important role in enhancing growth of the plants such as rice on Graminae particular group. Monocot plant needs Silica to support growth and production because Silica can repairing photosynthesis process. Now, the application of silica developed in the form of nanosilica since it meets the target, and required in a very small amount. This study aim to assess the effect of nanosilica fertilizer on the growth brown rice paddy. This study uses a completely randomized design. The concentration of fertilizer nanosilica given P0 ( $0 \mathrm{ml} / \mathrm{L}), \mathrm{P} 1(2.5 \mathrm{ml} / \mathrm{L}), \mathrm{P} 2$ $(5 \mathrm{ml} / \mathrm{L}), \mathrm{P} 3(7.5 \mathrm{ml} / \mathrm{L})$ and, $\mathrm{P} 4(10 \mathrm{ml} / \mathrm{L})$. Growth parameters are observed among other plant height and the number of tillers. Data were analyzed using the Analysis of Variance (ANOVA) followed by Duncan's 
Multiple Range Test Test (DMRT) at the 95\% significance level. P1-P4 Generally nanosilica fertilizer increases growth in brown rice. The results of this study indicate that the most optimal fertilization is $\mathrm{P} 4$ $(10 \mathrm{ml} / \mathrm{L})$. P4 significant results as follows plant height $106,40 \mathrm{~cm}$, the number of vegetative tillers 40.20 plants. The pattern of plant height growth tends to still increase to 40 HST, but the vegetative seedling growth pattern tends to slow down at $40 \mathrm{HST}$.

Keywords: brown rice,growth, nanosilica

\section{PENDAHULUAN}

Padi beras merah (Oryza sativa L. var. indica) telah dikembangkan untuk mendukung pangan fungsional yang dibutuhkan oleh masyarakat. Menurut Indrasari dan Adnyana (2007), beras merah termasuk dalam pangan fungsional karena memiliki komponen antosianin yang berguna bagi kesehatan.Antosianin adalah senyawa fenolik yang termasuk kelompok flavonoid dan berfungsi sebagai antioksidan. Menurut Kristamtini dan Purwaningsih (2009), padi beras merah memiliki prospek kedepan yang baik untuk dibudidayakan lebih lanjut. Hal ini berkaitan dengan kesadaran akan pentingnya kesehatan membuat masyarakat mulai mengkonsumsi beras merah, sehingga permintaan pasar terhadap beras merah semakin meningkat.

Permintaan beras merah semakin hari semakin meningkat dan disisi lain ketersediaan pasar sangat terbatas. Produksi beras merah masih rendah yaitu sekitar 2-3 ton/ha. Tingginya permintaan konsumen yang tidak diimbangi dengan pengembangan produksi sehingga diperlukan inovasi teknologi untuk memperbaki produktivitas beras merah (Kristamtini dan Purwaningsih, 2009).

Pemupukan merupakan salah satu cara meningkatkan pertumbuhan, produksi dan kualitas tanaman padi. Pupuk memiliki peran menambah unsur hara yang dibutuhkan tanaman. Sementara itu, lahan pertanian di Indonesia banyak yang mengalami leaching unsur hara mikro termasuk Si. Kandungan Si tersedia di dalam tanah sawah tidak berbanding lurus dengan kandungan totalnya. Ketersediaan Si di dalam tanah terutama di daerah tropis sangat rendah disebabkan oleh proses desilikasi. Proses desilikasi adalah proses pencucian dan intensitas pelapukan yang tinggi, akibatnya Si yang terdapat pada lapisan atas tanah tercuci ke lapisan bawah. Kondisi ini berakibat jumlah Si pada lapisan atas tanah menurun, sedangkan $\mathrm{Fe}$ dan $\mathrm{Al}$ terakumulasi pada permukaan tanah. Semakin tinggi kandungan Al dan Fe oksida dalam tanah mengakibatkan Si yang terlarut menjadi rendah (Husnain, 2011).

Kandungan total $\mathrm{Si}$ dalam tanah mineral sangat tinggi $( \pm 50 \%)$, namun ketersediaannya bagi tanaman sering kali sangat rendah. Tingkat ketersediaan hara $\mathrm{Si}$ bagi tanaman dipengaruhi oleh beberapa faktor, yaitu suhu tanah, potensial redoks (Eh), pH atau keasaman tanah, dan konsentrasi Si dalam larutan tanah. Oleh karena itu, ketersediaan $\mathrm{Si}$ pada tanah sawah tidak berkorelasi positif dengan kandungan total $\mathrm{Si}$ dalam tanah. Pada pertanaman padi memerlukan $\mathrm{Si}$ sebanyak $230-470 \mathrm{~kg} / \mathrm{ha}$. Rendahnya ketersediaan $\mathrm{Si}$ pada tanah sawah merupakan salah satu penyebab penurunan produktivitas tanaman padi (Husnain, 2011). Salah satu upaya manajemen pengolahan tanah adalah penggunaan jenis pupuk yang mampu mengembalikan unsur Si yaitu pupuk silika. Pupuk silika akan mengembalikan keadaan tanah agar kebutuhan unsur mikro silika terpenuhi.

Silika merupakan salah satu unsur fungsional yang memiliki peran penting dalam meningkatkan pertumbuhan tanaman khususnya kelompok famili Graminae seperti padi (Makarim, dkk. 2007). Silika diserap oleh tanaman dalam bentuk asam monosilikat masuk ke dalam tanaman melalui xylem dan ditransport bersama-sama dengan air, ditranslokasikan ke daun kemudian air menguap dan silika tersimpan dalam lapisan epidermis daun dalam bentuk silika amorf (Ma and Yamaji, 2006). Peran Si dalam meningkatkan pertumbuhan dan produksi padi disebabkan oleh membaiknya sistem fotosintesis karena daun menjadi lebih tegak, sehingga fotosintesis dapat berjalan dengan lancar sehingga dapat meningkatkan pertumbuhan tanaman (Yukamgo dan Yuwono, 2007). 


\section{BAHAN DAN METODE}

\section{Waktu dan Tempat Penelitian}

Penelitian ini dilakukan di daerah Tembalang, Semarang, Jawa Tengah. Pada bulan April-Agustus 2016.

\begin{abstract}
Alat dan Bahan
Alat yang digunakan adalah sekop, penggaris, label, meteran, ember, kamera, dan alat tulis. Bahan yang digunakan adalah benih beras merah, tanah sebagai media tumbuh, pupuk kompos, pupuk anorganik $\mathrm{N}$ (urea), TSP, $\mathrm{K}(\mathrm{KCl})$, Pupuk nanosilika berbahan dasar silika kristalin dan air.
\end{abstract}

\section{Cara Kerja}

Cara kerja meliputi: persiapan media tanaman, seleksi dan perkecambahan benih persemaian padi, penanaman bibit ke dalam ember plastik. Pemupukan tanaman padi dilakukan dengan menggunakan pupuk dasar (urea, TSP, dan $\mathrm{KCl}$ ) (Wangiyana, 2009). Pemberian air dilakukan setiap hari sampai menggenang kurang lebih $2 \mathrm{~cm}$ di atas permukaan tanah, kemudian pada 14 hari menjelang panen dibiarkan mengering (tanpa pengairan). Penelitian ini menggunakan 5 perlakuan, yaitu perlakuan kontrol (tanpa pemberian nano silika) dan perlakuan dengan pemberian nano silika dengan 4 taraf konsentrasi pupuk nanosilika yang berbeda yaitu $2,5 \mathrm{ml} / \mathrm{L}$; $5 \mathrm{ml} / \mathrm{L} ; 7,5 \mathrm{ml} / \mathrm{L} ; 10 \mathrm{ml} / \mathrm{L}$. Perlakuan pupuk $\mathrm{Si}$ dilakukan dengan cara penyemprotan pada seluruh bagian tanaman sebanyak 10ml. Penyemprotan Si dilakukan ketika tanaman berumur 10, 20, 30, 40, HST. Parameter tinggi tanaman dan jumlah anakan diamati setiap 10hari sekali.

\section{Pengamatan Pertumbuhan}

\section{Tinggi Tanaman}

Pengamatan tinggi tanaman mulai dari 10 HST - 40 HST. Tinggi tanaman diukur mulai pangkal batang dari permukaan tanah sampai ujung daun tertinggi dari tanaman.

\section{Jumlah Anakan Vegetatif}

Jumlah anakan vegetatif dengan menghitung jumlah anakan per rumpun dilakukan mulai dari 10 HST- 40 HST.

\section{Pola Pertumbuhan Tinggi dan Jumlah Anakan Vegetatif}

Pengamatan pola dilakukan setiap 10 hari sekali mulai hari 10 HST-40 HST

\section{HASIL DAN PEMBAHASAN}

Pengaruh pemberian pupuk nanosilika terhadap pertumbuhan diperoleh hasil bahwa pemberian pupuk nanosilika memberikan pengaruh nyata terhadaptinggi tanaman dan jumlah anakan vegetatif.

Tabel 1. Rata-rata Tinggi tanaman dan Jumlah anakan Padi Beras Merah dengan perlakuan pupuk nanosilika yang berbeda sampai 40 HST.

\begin{tabular}{lll}
\hline $\begin{array}{l}\text { Konsentrasi } \\
\text { Pupuk (ml/L) }\end{array}$ & $\begin{array}{l}\text { Tinggi } \\
\text { Tanaman } \\
(\mathrm{cm})\end{array}$ & $\begin{array}{l}\text { Jumlah } \\
\text { Anakan }\end{array}$ \\
\hline P0 $($ Kontrol $)$ & $85,80^{\mathrm{c}}$ & $30,40^{\mathrm{e}}$ \\
P1 $(2,5 \mathrm{ml} / \mathrm{L})$ & $86,20^{\mathrm{c}}$ & $31,00^{\mathrm{e}}$ \\
P2 $(5 \mathrm{ml} / \mathrm{L})$ & $95,40^{\mathrm{b}}$ & $34,00^{\mathrm{e}}$ \\
P3 $(7,5 \mathrm{ml} / \mathrm{L})$ & $99,60^{\mathrm{ab}}$ & $35,00^{\mathrm{de}}$ \\
P4 $(10 \mathrm{ml} / \mathrm{L})$ & $106,40^{\mathrm{a}}$ & $40,20^{\mathrm{d}}$ \\
& & \\
\hline
\end{tabular}

Keterangan: Angka yang diikuti huruf yang sama pada kolom yang sama menunjukkan pengaruh yang tidak berbeda nyata berdasarkan uji Duncan dengan taraf kepercayaan $95 \%$.

\section{Tinggi Tanaman}

Berdasarkan Tabel 1 menunjukkan bahwa permberian pupuk nanosilika memberikan pengaruh meningkatkan tinggi tanaman. Perlakuan P4 $(10 \mathrm{ml} / \mathrm{L})$ menunjukkan rata-rata tinggi tertinggi yaitu $106,40 \mathrm{~cm}$, sedangkan rata-rata tinggi tanaman terendah pada perlakuan P0 (kontrol) sebesar $85,80 \mathrm{~cm}$ sampai hari ke 40 HST. Hasil uji lanjut DMRT (Duncan's Multiple Range Test) dengan taraf signifikansi 95\% menunjukkan bahwa perlakuan P2 (5ml/L), P3 (7,5ml/L), P4 (10ml/L) 
memiliki pengaruh yang berbeda nyata dengan P0 (kontrol) dan P1 (2,5ml/L). Silika dapat meningkatkan kegiatan fotosintesis sehingga pertumbuhan tinggi tanaman semakin meningkat, sehingga tanaman yang diberi perlakuan pupuk nanosilika memiliki pertumbuhan tinggi yang lebih baik daripada kontrol.

Menurut Yukamgo dan Yuwono (2007), tinggi tanaman meningkat dikaitkan dengan peran Si mempengaruhi ketegakan daun sehingga dapat meningkatkan kegiatan fotosintesis. Meningkatnya hasil fotosintesis akan menggiatkan pembelahan sel, sehingga tinggi tanaman dapat meningkat. Menurut Harjanti, dkk. (2014), tinggi tanaman merupakan bentuk peningkatan pembelahan sel akibat meningkatnya asimilat. Savant et al. (1999) menyatakan bahwa Si mungkin saja terlibat dalam pemanjangan dan pembelahan sel. Pikukuh, dkk (2015), menambahkan efektifitas pemupukan Si meningkatkan pertumbuhan tinggi tanaman secara signifikan karena daun dan batang menjadi lebih tegak. Batang tanaman merupakan bagian sink dan kegiatan pemanjangan sel.

\section{Pola Pertumbuhan Tinggi Tanaman}

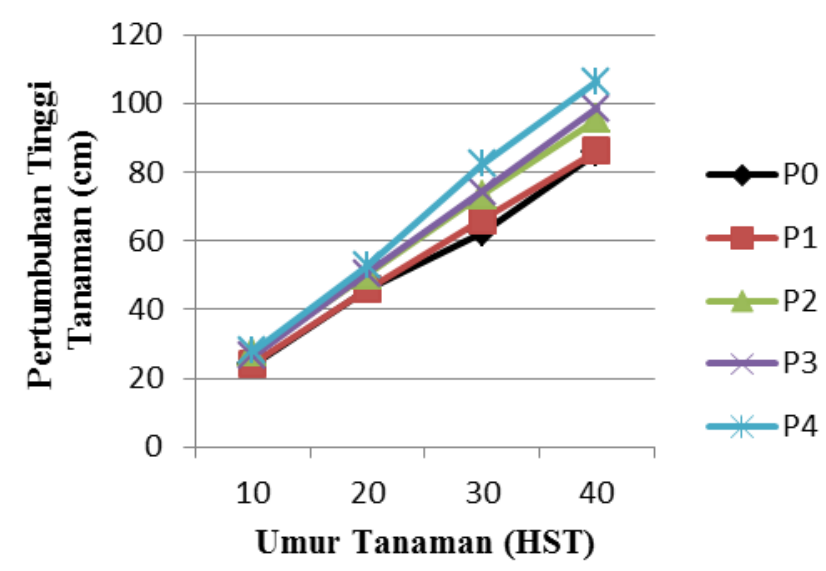

Gambar 1. Pola pertumbuhan tinggi tanaman pada umur 10 HST- 40 HST

Berdasarkan Gambar 1. Pola pertumbuhan tinggi tanaman meningkat dengan bertambahnya umur tanaman. Sampai dengan 40 HST belum didapatkan pertumbuhan tinggi tanaman optimum karena tanaman cenderung terus tumbuh melakukan pembelahan sel dan pertambahan tinggi tanaman. Pola pertumbuhan tinggi tanaman dengan perlakuan pupuk nanosilika dengan konsentrasi yang berbeda menunjukkan bahwa perlakuan pupuk nanosilika meningkatkan pertumbuhan tinggi tanaman. Perlakuan P4 menunjukkan pola pertambahan lebih tinggi dibanding perlakukan lainnya serta kontrol.

Pola pertumbuhan tinggi tanaman pada umur 10-20 HST memiliki rata-rata tinggi yang relatif sama, namun perlakuan P2, P3 dan P4 menunjukkan peningkatan tinggi yang lebih besar daripada perlakuan lain. Pada umur 20-40 HST perlakuan P4 (10ml/L) menunjukkan peningkatan tinggi tanaman yang lebih besar dari pada perlakuan lainnya. Menurut Yukamgo dan Yuwono (2007), Si dapat meningkatkan pola pertumbuhan tinggi tanaman karena $\mathrm{Si}$ mampu mempengaruhi ketegakan daun sehingga dapat meningkatkan kegiatan fotosintesis. Kegiatan fotosintesis yang meningkat dapat meningkatkan pertumbuhan tanaman, dalam penelitian ini yang teramati adalah pertumbuhan tinggi tanaman padi beras merah.

\section{Jumlah Anakan Vegetatif}

Hasil uji ANOVA (Analysis of Variance) menunjukkan pengaruh yang berbeda nyata, dimana pemberian pupuk nanosilika meningkatkan jumlah anakan vegetatif. Rata-rata jumlah anakan vegetatif semakin meningkat dengan pemberian pupuk nanosilika (Tabel 1.) Hal ini menunjukkan bahwa semakin tinggi konsentrasi pupuk nanosilika maka jumlah anakan vegetatif semakin meningkat. Jumlah anakan vegetatif paling tinggi terdapat pada perlakuan pupuk nanosilika P4 $(10 \mathrm{ml} / \mathrm{L})$ yaitu 41,20 tanaman, sedangkan P0 (kontrol) memiliki jumlah anakan yang paling sedikit yaitu 30,40 tanaman. Hasil uji lanjut DMRT (Duncan's Multiple Range Test) dengan taraf signifikansi $95 \%$ menunjukkan bahwa P0 (kontrol) dan P1 $(2,5 \mathrm{ml} / \mathrm{L})$, perlakuan P2 $(5 \mathrm{ml} / \mathrm{L})$ dan P3 $(7,5 \mathrm{ml} / \mathrm{L})$ memiliki pengaruh yang berbeda nyata dengan $\mathrm{P} 4(10 \mathrm{ml} / \mathrm{L})$.

Pemberian pupuk nanosilika meningkatkan jumlah anakan vegetatif, karena silika dapat meningkatkan kegiatan fotosintesis. Kegiatan fotosintesis yang berlangsung dengan baik dapat 
meningkatkan pertumbuhan tanaman sehingga jumlah anakan semakin meningkat. Yohana (2013), menambahkan akumulasi asimilat selama proses fotosintesis dapat meningkatkan jumlah anakan. Keberadaan $\mathrm{Si}$ dapat menggiatkan pembentukan anakan yang ditentukan oleh kegiatan pembelahan sel.

\section{Pola Pertumbuhan Jumlah Anakan}

Perlakuan pupuk silika meningkatkan pertumbuhan jumlah anakan vegetative, seperti terlihat pada Gambar 2.

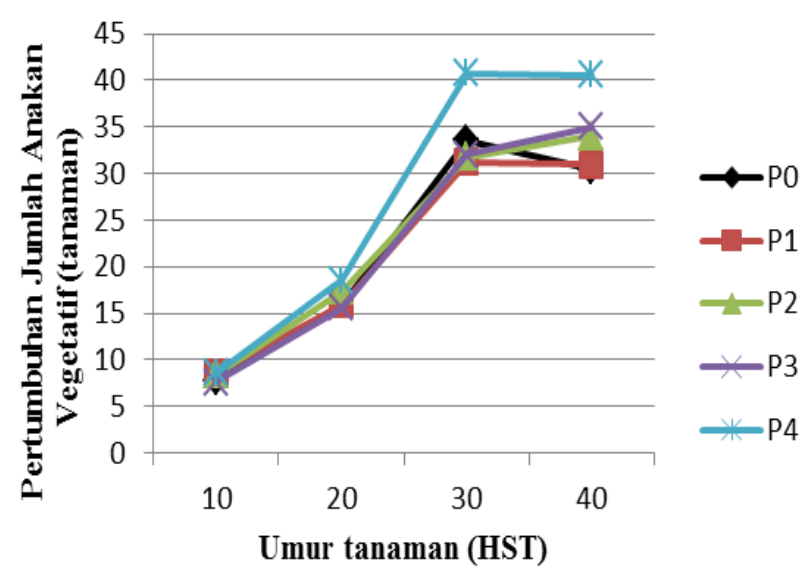

Gambar 2. Pola pertumbuhan jumlah anakan vegetatif pada umur 10-40 HST

Berdasarkan Gambar 2., pola pertumbuhan jumlah anakan vegetatif terus meningkat dari 1030 HST, dan perlakuan P4 menunjukkan hasil lebih tinggi dibanding perlakuan lain serta kontrol. Namun pada 30-40 HST menunjukkan hasil yang cenderung stagnan atau bahkan menurun.

Hasil penelitian sebelumnya oleh Amrullah (2015), tanaman padi yang diberi perlakuan 20 ppm nanosilika memiliki jumlah anakan yang lebih banyak dibandingkan perlakuan lain. Hal ini sejalan dengan penelitian $\mathrm{Ma}$ and Takahashi (2002), yang menunjukkan bahwa pemberian silika dapat meningkatkan tinggi tanaman, jumlah anakan, dan bobot tajuk.

Pertumbuhan dimulai secara perlahan-lahan kemudian melewati fase pertambahan besar yang cepat dan diikuti pertumbuhan rata-rata yang menurun secara gradual sampai ke titik terhentinya tumbuh (Hidayah, 2013). Menurut Yohana (2013), pembentukan anakan berlangsung sejak munculya anakan pertama sampai pembentukan anakan maksimum, sehingga bisa diduga pada padi beras merah pola pertumbuhan jumlah anakan vegetatif mengalami fase perlambatan dan penurunan pada 40 HST.

\section{KESIMPULAN}

Perlakuan pupuk nanosilika pada berbagai konsentrasi: P0 $(0 \mathrm{ml} / \mathrm{L}), \quad$ P1 $(2,5 \mathrm{ml} / \mathrm{L}), \quad$ P2 $\quad(5$ $\mathrm{ml} / \mathrm{L}), \quad \mathrm{P} 3(7,5 \mathrm{ml} / \mathrm{L}), \quad \mathrm{P} 4(10 \mathrm{ml} / \mathrm{L})$ memberikan hasil peningkatan pertumbuhan, dimana perlakuann $\mathrm{P} 4(10 \mathrm{ml} / \mathrm{L})$ memberikan pengaruh yang paling tinggi dalam meningkatkan tinggi tanaman dan jumlah anakan vegetatif padi beras merah (Oryza sativa L. var. indica). Pola pertumbuhan tinggi tanaman cenderung masih meningkat sampai 40 HST, namun pola pertumbuhan anakan vegetatif cenderung melambat pada 40 HST.

\section{DAFTAR PUSTAKA}

Amrullah. 2015. Pengaruh Nano Silika Terhadap Pertumbuhan, Respon Morfofisiologi dan Produktivitas Tanaman Padi (Oryza sativa L.). Disertasi. Institut Pertanian Bogor. Bogor.

Harjanti, RA., Tohari, SNH Utami. 2014. Pengaruh Takaran Pupuk Nitrogen dan Silika Terhadap Pertumbuhan Awal Tebu (Saccharum officinarum L.) Pada Inceptisol. Vegetalika. 3(2): 35-44.

Husnain. 2011. Sumber Hara Silika untuk Pertanian. Warta Penelitian dan Pengembangan Pertanian, 33(3) : 12-13.

Indrasari, S. D., dan Adnyana, M. O., 2007. Preferensi Konsumen terhadap Beras Merah sebagai Sumber Pangan Fungsional. Iptek TanamanPangan. 2(2) : 227-241.

Kristamtini dan Purwaningsih, H. 2009. Potensi Pengembangan Beras Merah Sebagai Plasma Nutfah Yogyakarta. Jurnal Litbang Pertanian 28 (3). 
Ma, J. F. and E, Takahashi. 2002. Soil, Fertilizer, and Plant Silicon Research in Japan. Elsevier, Amsterdam.

Ma, J.F. and N. Yamaji. 2006. Silicon Uptake and Accumulation in Higher Plants. Journal Okayama University. Japan.

Makarim A, E. Suhartatik, A. Kartohardjono.2007. Hara Penting pada Sistem Produksi Padi. Iptek Tanaman Pangan 2 (2) : 195-204.

Pikukuh, P., Djajadi, Tyasmoro, S.Y., dan Aini, N., 2015. Pengaruh Frekuensi dan Konsentrasi Penyemprotan Pupuk Nano Silika (Si) Terhadap Pertumbuha Tanaman Tebu (Saccharum officinarum L.). Jurnal Produksi Tanaman 3 (3) :249-258.

Savant, N. K, Korndorfer, G. H., Datnoff, L. E. and Snyder, G. H. 1999. Silicon nutrition and Sugarcane Production: a review. Journal Plant and Nutrition. 22 (12): 18531903.

Wangiyana, W. 2009. Pertumbuhan dan Hasil Tanaman Padi Var. Ciherang dengan Teknik Budidaya "SRI (System of Rice Intesification)" pada Berbagai Umur dan Jumlah Bibit per Lubang Tanam.Crop Agro 1 (2):70-78.

Yohana, O. 2013. Pemberian Bahan Silika pada Tanah Sawah Berkadar P Total Tinggi untuk Memperbaiki Ketersediaan P dan Si Tanah, Pertumbuhan dan Produksi Padi (Oryza sativa L.). Jurnal Online Agroekoteknologi. 1(4):1-9.

Yukamgo, E, dan N.W. Yuwono.2007. Peran Silikon Sebagai Unsur Bermanfaat pada Tanaman Tebu.Jurnal Ilmu Tanah dan Lingkungan, 7(2) : 103-116. 